\title{
IDEOLOGIA DE GÊNERO: O QUE DIZEM PERIÓDICOS BRASILEIROS?
}

\section{GENDER IDEOLOGY: WHAT DO BRAZILIAN PERIODICS SAY?}

\author{
Edmarcius Carvalho Novaes - UNIVALE/MG, Brasil \\ Jakeline Soares de Andrade - UNIVALE/MG, Brasil \\ Tainara Adriane dos Santos - UNIVALE/MG, Brasil
}

\begin{abstract}
RESUMO: A proposta deste artigo é analisar como a tida Ideologia de Gênero tem sido abordada em periódicos brasileiros de distintas áreas do conhecimento. Trata-se de uma investigação de natureza quantitativa e qualitativa, cuja metodologia é a realização de estudo da arte de produções acadêmicas que apresentam a discussão. Os resultados encontrados em quinze publicações apontam que a temática é pertinente, devido às conjecturas atuais que colocam em xeque o saber científico sobre as questões relativas às identidades de gênero e orientações sexuais. Conclui-se necessário transpor algumas preconcepções, uma vez que isto implica em consolidar o respeito às diversas identidades.
\end{abstract}

Palavras-chave: Educação. Estado da Arte. Identidade de gênero. Ideologia de Gênero. Orientação Sexual.

ABSTRACT: The purpose of this paper is to analyze how the Gender Ideology has been approached in Brazilian journals from different areas of knowledge. This is a quantitative and qualitative research, whose methodology is the study of the art of academic productions that present the discussion. The results found in fifteen publications indicate that the theme is pertinent, due to the current conjectures that question the scientific knowledge on issues related to gender identities and sexual orientations. It is concluded that it is necessary to overcome some preconceptions, as this implies consolidating respect for the various identities.

Keywords: Education. State of art. Gender identity. Gender Ideology. Sexual orientation.

\section{INTRODUÇÃO}

No campo acadêmico, pesquisas de diversas áreas do conhecimento pautam questões sobre as identidades de gêneros e orientações sexuais e demonstram a necessidade de eliminar desigualdades estabelecidas culturalmente entre homens e mulheres. A pauta atual de maior relevância destes cientistas é a necessidade de se refutar o que popularmente se tornou conhecido como Ideologia de Gênero. Segundo os estudos de gênero, trata-se de uma violência simbólica, uma vez que a proposta é carregada de um discurso político que visa manter uma hierarquia social a partir de aspectos de gênero, em que o homem detém o poder em detrimento da mulher.

Educação, Psicologia e Interfaces, Volume 4, Número 2, p. 35-50, Abril/Junho, 2020.

ISSN: 2594-5343. DOI: 10.37444/issn-2594-5343.v4i2.226 
Disseminada sobretudo por políticos e religiosos, seus defensores refutam o que a ciência (notadamente, a antropológica) aponta: o fato de que ninguém nasce homem e nem mulher, mas que assim se constitue, culturalmente, em sua sociedade. Isto significa que para os estudos de gênero, as identidades de gênero e as orientações sexuais estão para além de meros aspectos biológicos; tratam-se de construções sociais, e como tal devem ser garantidos com respeito, e suas diversas manifestações reconhecidas.

Neste sentido, este trabalho problematiza como os artigos científicos brasileiros, publicados em periódicos de diversas áreas do conhecimento, tem percebido a utilização desta terminologia. Sua relevância consiste na representação que tal perspectiva dá às identidades de gênero e que torna parte significativa de um processo político de invisibilidade de determinadas minorias. Ainda, há um papel normativo, pois conforme Judith Butler (2010), esta representação reflete à desigual produção social sobre gênero, uma vez que aspectos que fogem do simples caráter dicotômico homem versus mulher não têm a mesma relevância.

O objetivo desta produção é indagar se as produções encontradas, pela realização de um estado da arte, de fato indicam que a percepção de uma pessoa sobre sua identidade de gênero não é uma mera escolha, mas que se trata de um processo complexo de entendimento sobre sua própria constituição identitária e de como se reconhece enquanto indivíduo, à partir do espectro de gênero - o que refuta cabalmente os argumentos apresentados por aqueles que defendem a atual proposta da Ideologia de Gênero.

\section{MATERIAL E MÉTODO}

A presente pesquisa, de caráter quantitativo e qualitativo, visa a produção do estado da arte de artigos que abordam as discussões sobre gênero, em diferentes áreas do conhecimento. A produção do estado da arte se faz importante para se ter um panorama atual do debate, pois gênero, cientificamente, é uma categoria de análise à ser percebida como um componente essencial nas relações sociais, e que influencia significativamente nas maneiras de aparelhamento sociocultural e seus diferentes contextos.

A preferência pela metodologia adotada se deu por compreender sua contribuição nas pesquisas acadêmicas. Uma pesquisa deste tipo, segundo Norma Ferreira (1995, p. 257) é aquela que tem “(...) o desafio de mapear e de discutir uma certa produção

Educação, Psicologia e Interfaces, Volume 4, Número 2, p. 35-50, Abril/Junho, 2020. 
acadêmica em diferentes campos do conhecimento, tentando responder que aspectos e dimensões vêm sendo destacados e privilegiados em diferentes épocas e lugares".

Para sua realização, utilizamos como base a plataforma SciELO (Scientific Electronic Library Online), no período de 27 anos, correspondente à 1991-2018, em razão dos indicativos teóricos de que a discussão sobre a Ideologia de Gênero tenha surgido no início dos anos 90. Buscou-se, então, pelos termos específicos 'Ideologia de gênero' e 'gênero'. O percurso da pesquisa seguiu com a seleção dos seguintes campos de critérios: "pesquisa de modo integrado"; "Brasil"; "todos as áreas" (do conhecimento), além do recurso das palavras chaves acima descritas.

\section{Gráfico 1 - Quantificação dos artigos pesquisados por ano}

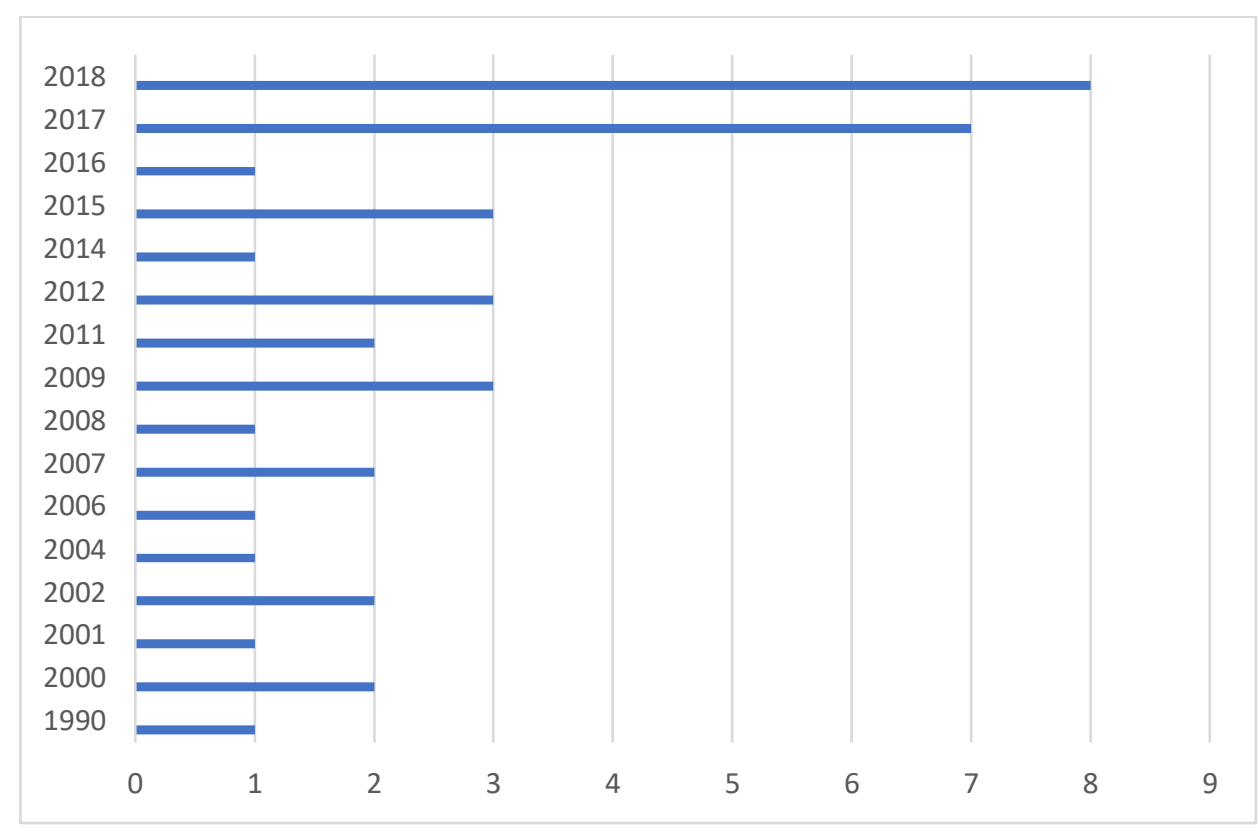

Fonte: dados dos autores (2019)

Após a realização da pesquisa foi possível ter uma melhor compreensão de como as produções cientificas que tratam da Ideologia de gênero, são recebidas e publicadas em periódicos de relevância acadêmica, em razão de suas classificações no quadriênio 2013-2016, pelas normativas da Coordenação de Aperfeiçoamento de Pessoal de Nível Superior (CAPES) do Ministério da Educação, entre os tipos A1, A2, B1, B2, B3, B4, B5 e $\mathrm{C}$, respectivamente.

\section{Gráfico 2 - Quantificação dos artigos por classificação Qualis CAPES}




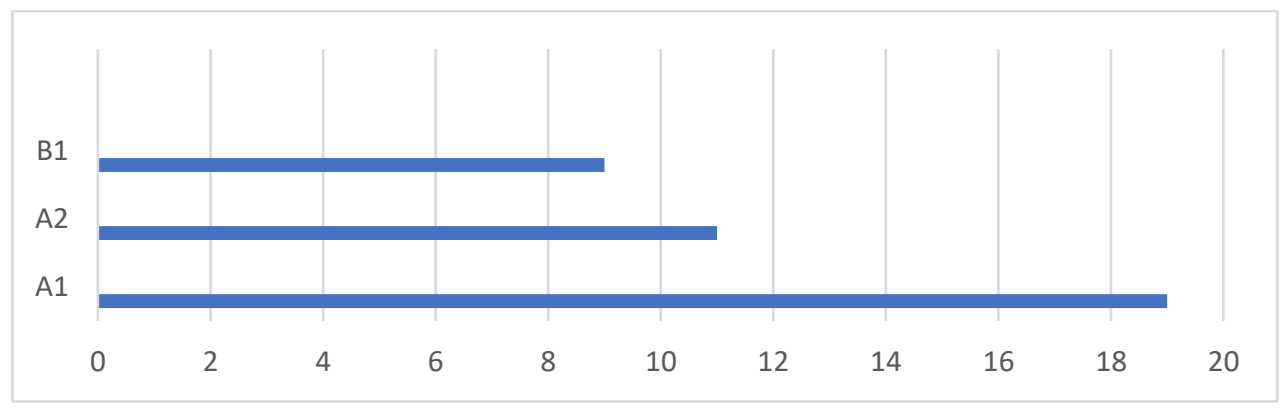

Fonte: dados dos autores (2019)

No primeiro momento, foram encontrados 39 artigos, organizados por ano de publicação e, posteriormente, por categoria de análise. Destes, apenas 15 tratavam da discussão sobre a Ideologia de Gênero e problematizavam-a enquanto condição humana (os demais referiam-se à gêneros literários, musicais, artísticos, etc.). Quando analisadas as áreas do conhecimento dos 15 artigos analisados, tem-se a seguinte situação:

Gráfico 3 - Quantificação dos artigos por áreas do conhecimento

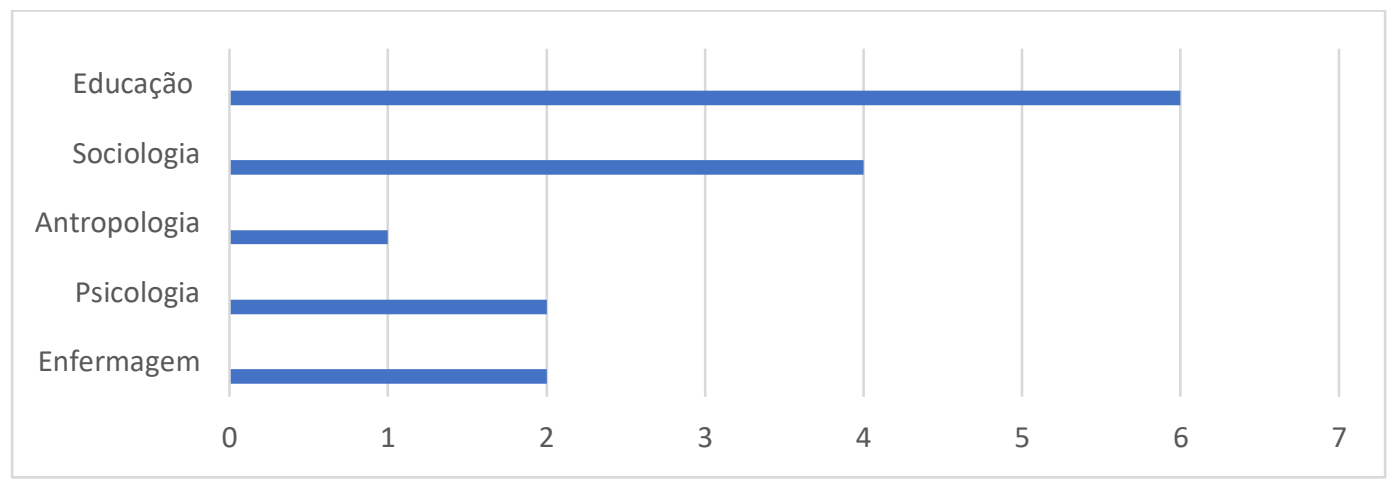

Fonte: dados dos autores (2019)

\section{RESULTADOS E DISCUSSÃO}

$\mathrm{Na}$ área da Enfermagem, o primeiro artigo analisado é assinado por Ceci Vilar Noronha e Maria Esther Daltro (1991), publicado no Cadernos de Saúde Pública, da Escola Nacional de Saúde Pública Sergio Arouca, Fundação Oswaldo Cruz (ENSPFIOCRUZ). Intitulado “A violência masculina é dirigida para Eva ou Maria?”, analisa diferenciais por gênero de mortes violentas ocorridas na Bahia. Aponta a generalização do domínio masculino sobre a mulher na interpretação de reações violentas. Como resultados e conclusões apresenta a necessidade de se fazer resistência a ideologia de gênero, que inferioriza o que a mulher significa, e que, simultaneamente, evita

Educação, Psicologia e Interfaces, Volume 4, Número 2, p. 35-50, Abril/Junho, 2020. 
agressões e homicídios. Ainda, que superar a assimetria nas relações que regem os papéis masculinos e femininos é algo desafiante, mas que para tanto, é preciso compreender o grau de participação das mulheres na sua própria vitimização.

O segundo artigo da área é assinado por Janaina Marques de Aguiar e Regina Helena Simões (2006), também publicado no Cadernos de Saúde Pública, da Escola Nacional de Saúde Pública Sergio Arouca, Fundação Oswaldo Cruz (ENSPFIOCRUZ), intitulado "Relações entre profissionais de saúde e mulheres HIV+: uma abordagem de gênero". As autoras objetivavam contribuir para a melhoria da qualidade na assistência à saúde das mulheres HIV+, promovendo e respeitando, como preconiza o PAISM Política Nacional de Atenção Integral à Saúde da Mulher, o direito ao exercício pleno e consciente da sexualidade e da cidadania. Como resultados e conclusões apresentam que o modelo de assistência está perpassa por contradições e conflitos entre o tradicional modelo médico e as novas práticas propostas, o que aponta para a necessidade de profundas transformações no modelo assistencial para sua efetiva implementação. Evidenciam o quanto a situação de pobreza das pacientes perpassa o campo da assistência para o HIV/AIDS, e aponta para os limites provocados pela pauperização e feminização da epidemia na prática cotidiana dos serviços públicos de saúde. Coloca-se, dessa forma, a necessidade urgente de maiores investimentos em políticas públicas que reduzam os crescentes níveis de desigualdades sociais no país.

Já no campo da Psicologia, o primeiro artigo analisado é assinado por Berenice Bento e Larissa Pelúcio (2012), publicado na Revista Estudos Feministas, da Universidade Federal de Santa Catarina, intitulado "Despatologização do gênero: A politização das identidades abjetas". Na produção, as autoras indagam os motivos de se diagnosticar o gênero, quem autoriza psicólogos, psiquiatras, endocrinologistas e outras especialidades, que fazem parte das equipes multidisciplinares, a avaliarem as pessoas transexuais e travestis como "doentes", além de indagarem o fato de que se não existe nenhum exame clínico que conduza a produção do diagnóstico, como pode ser determinada a ocorrência do "transtorno", e como estabelecer os limites discerníveis entre "os transtornados de gênero" e "os normais de gênero". Assim, analisam a ideologia de gênero presente no DSM (Manual Diagnóstico e Estatístico de Transtornos Mentais, publicado pela Associação Americana de Psiquiatria) e no CID (Classificação Estatística Internacional de Doenças e Problemas Relacionados com a Saúde, publicada pela 
Organização Mundial de Saúde), que incorporam o gênero como uma categoria diagnóstica, e, por fim, apresentam argumentos pelo fim do diagnóstico de gênero. Como resultados e conclusões pontuam a preferência por nomear como "patologização do gênero" em vez de "psiquiatrização do gênero", por entenderem que há um conjunto de saberes polimorfos que se articulam para produzir as normas e os normais de gênero.

O segundo artigo da área dialoga com o Direito e é assinado por Roger Raupp Rios, Alice Hertzog Resadori, Rodrigo da Silva e Daniel Martins Vidor (2017). Intitulado "Laicidade e conselho federal de psicologia: Dinâmica Institucional e Profissional em Perspectiva Jurídica” foi publicado na Revista Psicologia: Ciência e Profissão, publicação do referido Conselho de Classe. Examinam os fundamentos e o modelo da laicidade constitucional no Brasil e refletem sobre as consequências desse modelo para a vida institucional e a fiscalização profissional do Conselho Federal de Psicologia - CFP. Apontam ser socialmente relevante a discussão, na medida em que a adoção de posturas democráticas nos debates públicos atuais sobre assuntos como a "cura gay" (objeto de ações liminares por alguns psicólogos que desejaram respaldo jurídico para a prática da terapia de reversão sexual, mas suspensa em 2019 pelo STF) e a "ideologia de gênero", as políticas públicas de saúde e o credenciamento de cursos de graduação em Psicologia, devem perpassar pela compreensão do conceito de laicidade e da sua aplicação ao CFP. Concluem que não há espaço para atividades institucionais e profissionais que incorram nessa confusão, ficando sem sentido adjetivações tais quais "Psicologia cristã", "Psicologia budista", "Psicologia islâmica", "Psicologia hindu" ou equivalentes, sempre que queiram expressar um saber, técnica ou procedimentos psicológicos orientados religiosamente. Ainda, a necessidade de afirmar a prevalência da laicidade como princípio organizador da vida institucional do Conselho Federal de Psicologia e como diretriz informadora, não só da atividade de fiscalização do exercício profissional da entidade, mas também da contribuição que a sociedade brasileira espera, para a concretização da vida democrática.

No campo da Antropologia, o único artigo encontrado é assinado por Pedro Paulo Gomes Pereira (2018), intitulado “Judith Butler e a pomba-gira”, e publicado no Cadernos Pagu da UNICAMP - Universidade Estadual de Campinas. Aborda a pressão que setores conservadores vêm exercendo contra as conquistas no campo de gênero e sexualidade, o que coloca a "religião" como um campo em disputa ou como perspectivas

Educação, Psicologia e Interfaces, Volume 4, Número 2, p. 35-50, Abril/Junho, 2020. 
em disputa com a ciência, a partir das produções do campo feminista, sobretudo da referida autora. Como resultados e conclusões apresenta que o caminho talvez seja o se encantar com a multiplicidade dos agentes e suas formas inauditas de agência, com a criatividade de suas poéticas. Para isto se faz necessário experimentar(se) (em)outros conceitos, aproximando-se de outros saberes e subjetividades afetadas por essas teoriasoutras e por outras práticas, em busca de uma poética no mundo dos possíveis.

Já na área da Sociologia, o primeiro artigo analisado é assinado por Maria das Dores Campos Machado (2018), intitulado "O discurso cristão sobre a "ideologia de gênero", também publicado na Revista de Estudos Feministas da Universidade Federal de Santa Catarina. A autora realiza uma genealogia do discurso cristão sobre a "ideologia de gênero" que se difundiu em nossa sociedade nos últimos anos e tem pautado uma série de projetos de leis em tramitação nas diferentes instâncias do poder legislativo brasileiro. Para tanto, analisa a disseminação deste discurso cristão na esfera política e na sociedade civil por parte de atores católicos e evangélicos que rejeitam a adoção da categoria de gênero nas políticas públicas, para perceber as questões que estão em jogo e a participação dos atores religiosos brasileiros nesta luta simbólica. Como resultados e conclusões apresenta que mostrar o caráter transnacional deste fenômeno que vem se desenvolvendo desde a década 90 do século passado, quando as ativistas feministas conseguiram legitimar a categoria gênero com a sua inserção em documentos das conferências sociais, é trabalhar a ideia da disputa moral e da construção social de uma nova forma de moralidade por parte dos movimentos sociais.

O segundo artigo analisado é assinado por Richard Miskolci (2018), intitulado “Exorcizando um fantasma: os interesses por trás do combate à 'ideologia de gênero", também publicado no Cadernos Pagu - UNICAMP. Busca identificar grupos e seus interesses em combater as discussões de gênero, analisar alianças e a gramática política de sua atuação, ao dissipar o espectro da "ideologia de gênero" e contribuir para desconstruir a política do medo e da perseguição que instaura contra intelectuais, artistas e educadores/as. Como resultados e conclusões apresenta que as evidências históricas indicam que vivemos um período de acirramento das disputas entre grupos estabelecidos e aqueles que demandam reconhecimento e direitos. Assim, sob o domínio do medo, grupos autoritários engendram ódio e ações persecutórias, o que faz necessário dissipar o fantasma da "ideologia de gênero" em que se apoiam, trazendo à luz o fato de que buscam 
manter subalternizados aqueles e aquelas que o conceito de gênero acolhe dentro do humano, buscando garantir-lhes igualdade jurídica, segurança e direito à vida.

O terceiro artigo da área da Sociologia é assinado por Fernando de Figueiredo Balieiro (2018), intitulado "Não se meta com meus filhos": a construção do pânico moral da criança sob ameaça”, publicado no Cadernos Pagu - UNICAMP. Neste, o autor analisa três episódios envolvidos no pânico criado em torno da temática de gênero: a reação, em 2011, contra materiais didáticos pelo enfrentamento da homofobia nas escolas; a discussão, entre 2014 e 2015, sobre planos educacionais na qual se difundiu a noção de "ideologia de gênero"; e, em 2017, a perseguição a exposições e performances artísticas em Porto Alegre e São Paulo que antecedeu a vinda de Judith Butler ao Brasil. Para o autor, a formação do pânico moral dependeu do recurso discursivo estratégico de transformar iniciativas que visassem promover avanços aos direitos sexuais, em ameaça às crianças. Como resultados e conclusões apresenta que os posicionamentos de empreendedores morais, acessados em discursos parlamentares, debates públicos com repercussões nas mídias convencionais, além de conteúdos difundidos nas redes sociais, possibilita a reflexão científica sobre uma estratégia discursiva que não apenas ajudou a barrar avanços relativos a direitos sexuais e reprodutivos no país, mas que levou à retrocessos evidentes, como a ameaça à própria liberdade intelectual e artística.

O quarto e último artigo da área da Sociologia é assinado por Richard Miskolci e Maximiliano Campana (2017), intitulado “Ideologia de gênero": notas para a genealogia de um pânico moral contemporâneo", publicado na Revista Sociedade e Estado, da UNB - Universidade de Brasília. Os autores retraçam a genealogia do termo para compreender a gramática política em que se insere. Para tanto, retomam textos que o definem já há 20 anos, mapeiam onde ele emerge na América Latina e quando passa a ser acionado contra avanços nos direitos sexuais e reprodutivos. Como resultados e conclusões apresentam que os empreendedores morais da "ideologia de gênero" são grupos de interesse conservadores que buscam distanciar os movimentos feminista e LGBT, e até mesmo seus simpatizantes, das definições de políticas públicas e tomá-las o controle. Dentro do recente campo discursivo de ação reconstituído no artigo, buscam delimitar o Estado como espaço masculino e heterossexual, portanto, refratário às demandas de emancipação feminina e de expansão de direitos e cidadania àqueles e àquelas que consideram ameaçar sua concepção de mundo tradicional.

Educação, Psicologia e Interfaces, Volume 4, Número 2, p. 35-50, Abril/Junho, 2020. 
$\mathrm{Na}$ área da educação, o primeiro artigo analisado apresenta uma discussão interdisciplinar (educação especial, direito e saúde), assinado por Olga Maria Barros e Suely Ferreira Deslandes (2012), intitulado "Sexualidade e deficiência intelectual: narrativas de pais de adolescentes”, e publicado na Revista Physis: Revista de Saúde Coletiva da UERJ - Universidade Estadual do Rio de Janeiro. As autoras investigam as narrativas sobre a sexualidade de adolescentes com deficiência intelectual, a partir do relato de seus responsáveis, e como esses cuidadores declararam comportar-se diante da expressão sexual dos filhos. Como resultados apresentam que a religiosidade se mostrou um fator importante na vida dos narradores. O meio social em que vivem, com influência de valores religiosos, de uma maneira geral, é revestido de muitos preconceitos em questões relacionadas à sexualidade. Contudo, são necessários outros estudos para um estabelecimento mais claro dessa relação. $O$ viés de gênero também foi fortemente representado nos relatos analisados, manifestado na aceitação das expressões da sexualidade masculina e negação das do gênero oposto. Aponta-se a necessidade de ampliação do debate com os adolescentes, seus pais e diversos setores da sociedade para minimizar os preconceitos em relação à sexualidade das pessoas com deficiência intelectual, propiciando a garantia de seus direitos sexuais.

O segundo artigo da área da educação é assinado por Naara Luna (2017), intitulado "A criminalização da "ideologia de gênero": uma análise do debate sobre diversidade sexual na câmara dos deputados em 2015", e publicado no Cadernos Pagu - UNICAMP. A autora objetiva elucidar o debate público sobre os direitos humanos no tocante a reivindicações relacionadas à diversidade sexual, identificando seus principais atores e os argumentos usados, e para isso verifica que tipos de argumentação é acionada no debate público: argumentos referentes à ordem da natureza, entranhados em discurso científico ou naturalizante, argumentos da esfera legal e do direito, e argumentação religiosa. Como resultados e conclusões apresenta uma reação que demanda excluir os temas transversais referentes a gênero e sexualidade no sistema de educação, pois os parlamentares que se pretendem defensores da família, na maioria dotados de identidade religiosa, pretenderiam recuperar o espaço perdido historicamente - o que revela por parte de parlamentares uma intensa mobilização contrária às reivindicações de direitos pelo movimento LGBT. Ao analisar a movimentação da época, a autora concluiu que o projeto conservador ressuscitava a figura do homossexual como perigo para a saúde pública por 
conta de seu comportamento tido como promíscuo, além de aludir a uma série de moléstias incuráveis, implicando que todas seriam contagiosas.

O terceiro artigo da área é assinado por Maria Rita de Assis César e André de Macedo Duarte (2017), intitulado “Governamento e pânico moral: Corpo, gênero e diversidade sexual em tempos sombrios", publicado na Educar em Revista da Universidade Federal do Paraná. Analisam disputas contemporâneas em torno da sexualidade e do gênero nas discussões dos planos nacional, estadual e municipal de educação, com foco nas batalhas narrativas da presença dos conteúdos da igualdade de gênero e da diversidade sexual na educação brasileira, cujos aspectos se tornaram o centro de uma disputa pelo estabelecimento de novas formas de governamento do corpo e do desejo. Como resultados afirmam que os ataques recentes da chamada "ideologia de gênero" representam a disputa pela produção de uma nova governamentalidade de corpos, sexualidades e desejos. Concluem que o campo discursivo e institucional relativo ao corpo, ao gênero e à sexualidade está em disputa.

O quarto artigo analisado na área da Educação é assinado por Toni Reis e Edla Eggert (2017), intitulado “Ideologia de gênero: uma falácia construída”, publicado na Revista Educação e Sociedade, do CEDES - Centro de Estudos Educação e Sociedade. Com o objetivo de explorar a falácia da "ideologia de gênero" que aflorou nas discussões sobre os atuais Planos de Educação, os autores examinam argumentos de segmentos reacionários e/ou acríticos da sociedade contra a inclusão desses temas nos Planos de Educação. Como resultados apresentam que percebe-se que se formou uma aliança composta por evangélicos e católicos mais ortodoxos, quando não fundamentalistas, bem como organizações conservadoras/reacionárias que defendem o que chamam de família e costumes tradicionais, unidas em divulgar e disseminar informações distorcidas para impedir que se alcance a equidade entre os gêneros e o respeito à diversidade sexual, conforme vem sendo ratificado internacional e nacionalmente há décadas com a intenção de diminuir as discriminações e as violências baseadas em gênero. Ainda apontam para a necessidade do envolvimento de outros setores a fim de diminuir o enviesamento e contribuir para que a Educação brasileira incorpore a igualdade de gênero e o respeito à diversidade sexual.

O quinto artigo analisado é assinado por Ivanderson Pereira da Silva (2018), intitulado "Em busca de significados para a expressão "ideologia de gênero", $e$ 
publicado na Educação em Revista da Universidade Federal de Minas Gerais. Trata-se de uma investigação sobre os significados que têm sido produzidos pela expressão “Ideologia de Gênero" no cenário contemporâneo, e um mapeamento de publicações que contenham essa expressão em seu título e/ou resumo, explorando suas definições, bem como as propostas que são apresentadas. Como resultados e conclusões apresentam que constatou que a expressão "Ideologia de Gênero" tem assumido pelo menos três significados gerais: o machismo e a LGBT/fobia como ideologias de gênero; como um prelúdio do apocalipse moral (no campo religioso e no campo legislativo); e como uma falácia. $\mathrm{O}$ autor conclui que para se possa construir uma sociedade na qual, genuinamente, se defendam as famílias, as liberdades e a dignidade da pessoa humana, é fundamental que se compreenda, se desmascare e se desconstrua a falaciosa e mirabolante posição religiosa acerca da "Ideologia de Gênero".

Por fim, o sexto artigo da área da educação é assinado Rafaela Oliveira Borges e Zulmira Newlands Borges (2018), intitulado "Pânico moral e ideologia de gênero articulados na supressão de diretrizes sobre questões de gênero e sexualidade nas escolas”, e publicado na Revista Brasileira de Educação, da ANPEd - Associação Nacional de Pós-Graduação e Pesquisa em Educação. As autoras analisam as condições que possibilitaram as supressões de diretrizes sobre questões de gênero, identidade de gênero e orientação sexual dos planos estadual e municipal de educação do Rio Grande do Sul e Porto Alegre, para discutir o delineamento de políticas públicas na educação brasileira que articulam as temáticas de gênero e sexualidade. Como resultados identificam atores e argumentos colocados em ação na construção de um pânico moral em torno da categoria acusatória da "ideologia de gênero", problematizando tal categoria que culmina com as pequenas, mas significativas, alterações nos planos de educação.

De forma sucinta, as produções apontam que concepção de gênero se constitui a partir da consideração das experiências de cada pessoa, que podem corresponder ou não às suas identidades biológicas de nascimento, incluindo a decisão pessoal de cada um(a) sobre o seu próprio corpo. Isto ocorre pois trata-se de uma categoria sem caráter objetivo, já que “(...) o gênero é uma complexidade cuja totalidade é permanentemente protelada, jamais plenamente exibida em qualquer conjuntura considerada" (BUTLER, 2010, p. 37).

No decorrer das leituras dos artigos encontrados, é notório que a temática, sobretudo no contexto educacional e de saúde, para muitos parlamentares conservadores, 
é considerada uma ameaça à concepção de mundo tradicional. Entre os discursos em que se nota a presença da terminologia Ideologia de Gênero se destacam o religioso (judaicocristão) e o médico (biologizante/patologizante), que regulam corpos, identidades e sexualidades, através de construções simbólicas que limitam as possibilidades do ser em prol de uma dada ordem social, suas normas e sustentação intencional das relações de poder já vigorantes.

Destaca-se ainda que estes fatos devem ser vistos com atenção, pois quando o assunto é sobre questões de gênero e educação, em tese, tem-se a ideia de uma escola igualitária, espaço fundamental para os sujeitos estimularem pensamentos, aprendizagens e construírem suas personalidades. No entanto, as produções indicam que a educação quando pensada para a diversidade, não significa uma doutrinação como alegam os defensores da Ideologia de gênero; trata-se de um processo que possibilita a reflexão sobre as construções sociais e culturais, em especial, de seus papéis de gênero.

Se os tempos atuais se mostram limitadores das possibilidades de liberdade de identidades de gênero e orientação sexual, fazer a crítica ao uso do termo Ideologia de gênero se constitui uma abordagem social e politicamente necessária, face aos pensamentos tradicionais que se fortalecem, inevitavelmente, por estranhamentos e debates calorosos. Neste sentido, é importante no campo epistêmico ter mais compreensão sobre gênero como uma categoria de análise das relações sociais. Assim, a defesa de seu caráter conceitual e que aponta para uma construção social, significa fortalecer a visibilidade que os movimentos feministas e LGBTs tem conquistado, principalmente entre os meios de comunicação e com o advento da internet.

\section{CONSIDERAÇÕES FINAIS}

Este trabalho problematizou como algumas produções, publicizadas em periódicos de diversas áreas do conhecimento, apresentam a discussão sobre a existência de uma possível Ideologia de Gênero. As produções analisadas, a partir da realização do estado da arte, primeiramente, indicam que a percepção de uma pessoa sobre sua identidade de gênero não é uma escolha, mas uma constituição identitária sobre a forma como se reconhece como indivíduo a partir do espectro de gênero, independentemente de seu sexo biológico. Assim, o gênero é tido como uma categoria de análise, fruto de uma construção social e cultural.

Educação, Psicologia e Interfaces, Volume 4, Número 2, p. 35-50, Abril/Junho, 2020. 
Por outro lado, também apontam que aqueles que empregam a terminologia denominada Ideologia de Gênero o fazem de forma negativa, para refutar questões relacionadas ao gênero como condição humana e, portanto, levantam questionamentos com foco nos processos educativos em espaços escolares. Alegam, que muitos educadores, com viés ideológico, se posicionam contrários a mera explicação de gênero como sinônimo de sexo biológico, com o intuito de colidirem com valores familiares e religiosos e, numa perspectiva maior, induzir crianças e adolescentes às práticas sexuais de LGBTs e às mudanças de identidade de gênero.

Portanto, os artigos apontam a importância de uma educação em gênero para fazer com que confusões conceituais sobre as dimensões humanas correlatas às orientações sexuais e as identidades de gênero não se prolonguem. Os autores problematizaram as questões afetas às relações sociais e de poder nas quais se materializam formas de se viver a partir do que se acredita serem papéis sociais masculinos e femininos, e de uma sociedade cuja 'normalidade' é tida como a prática de uma sexualidade exclusivamente heterossexual. Resta a certeza de que o intuito da educação é a formação de toda sociedade; para tanto, a escola além de formar cidadãos para o mercado de trabalho, tem o importante papel de preparar o sujeito para vida, o que significa saber respeitar as diferentes formas pelas quais as pessoas constituem suas vidas e organizam suas orientações e práticas de afetividade e de sexualidade.

\section{REFERÊNCIAS BIBLIOGRÁFICAS}

AGUIAR, Janaína Marques de; SIMOES-BARBOSA, Regina Helena. Relações entre profissionais de saúde e mulheres HIV+: uma abordagem de gênero. Cad. Saúde Pública, Rio de Janeiro, v. 22, n. 10, p. 2115-2123, Out. 2006 . Disponível em: $<\mathrm{http}$ //Www.scielo.br/scielo.php?script=sci_arttext\&pid=S0102311X2006001000017\&lng=en\&nrm=iso >. Acesso em: 02 dez 2019. Doi: https://doi.org/10.1590/S0102-311X2006001000017.

BALIEIRO, Fernando de Figueiredo. "Não se meta com meus filhos": a construção do pânico moral da criança sob ameaça. Cad. Pagu, Campinas, n. 53, e185306, 2018 . Disponível em: <http://www.scielo.br/scielo.php?script=sci_arttext\&pid=S010483332018000200406\&lng=en\&nrm=iso>. Acesso em: 02 abril 2019. Epub June 11, 2018. Doi: https://doi.org/10.1590/18094449201800530006.

BASTOS, Olga Maria; DESLANDES, Suely Ferreira. Sexualidade e deficiência intelectual: narrativas de pais de adolescentes. Physis, Rio de Janeiro, v. 22, n. 3, p. 
1031-1046, 2012. Disponível em <http://www.scielo.br/scielo.php?script=sci_arttext\&pid=S0103-

73312012000300010\&lng=en\&nrm=iso>. Acesso em: 02 de maio de 2019. Doi: https://doi.org/10.1590/S0103-73312012000300010 .

Berento, Berenice; PELUCIO, Larissa. Despatologização do gênero: uma politização das identidades abjetas. Rev. Estud. Fem. , Florianópolis, v. 20, n. 2, p. 559-568, agosto de 2012. Disponível em <http://www.scielo.br/scielo.php?script=sci_arttext\&pid=S0104026X2012000200017\&lng=en\&nrm=iso>. Acesso em: 02 de maio de 2019. Doi: https://doi.org/10.1590/S0104-026X2012000200017 .

BORGES, Rafaela Oliveira; BORGES, Zulmira Newlands. Pânico moral e ideologia de gênero articulados na supressão de diretrizes sobre questões de gênero e sexualidade nas escolas. Rev. Bras. Educ., Rio de Janeiro , v. 23, e230039, 2018 . Disponível em: $<$ http://www.scielo.br/scielo.php?script=sci_arttext\&pid=S141324782018000100231\&lng=en\&nrm=iso>. Acesso em: 10 jan. 2019. Doi: https://doi.org/10.1590/s1413-24782018230039.

BUTLER, Judith. Problemas de gênero. Feminismo e subversão de identidade. Tradução de Renato Aguiar. Rio de Janeiro: Civilização Brasileira, 2010.

CESAR, Maria Rita de Assis; DUARTE, André de Macedo. Governo e moral moral: corpo, gênero e diversidade sexual em tempos sombrios. Educ. rev. , Curitiba, n. 66, p. 141-155, dezembro de 2017. Disponível em <http://www.scielo.br/scielo.php?script=sci_arttext\&pid=S010440602017000400141\&lng=en\&nrm=iso>. Acesso em: 02 de maio de 2018. Doi: https://doi.org/10.1590/0104-4060.54713 .

FERREIRA, Norma Sandra de Almeida. As pesquisas denominadas "estado da arte". Educ. Soc. , Campinas, v. 23, n. 79, p. 257-272, agosto de 2002. Disponível em $<$ http://www.scielo.br/scielo.php?script=sci_arttext\&pid=S0101$73302002000300013 \& \operatorname{lng}=e n \& n r m=i s o>$. Acesso em 02 de maio de 2019. Doi: https://doi.org/10.1590/S0101-73302002000300013 .

LUNA, Naara. A criminalização da "ideologia de gênero": uma análise do debate sobre diversidade sexual na Câmara dos Deputados em 2015. Cad. Pagu, Campinas, n. 50, e175018, 2017. Disponível em:

$<$ http://www.scielo.br/scielo.php?script=sci_arttext\&pid=S0104$83332017000200311 \& \operatorname{lng}=$ en $\& n r m=i s o>$. Acesso em 02 jan. 2019. Doi: https://doi.org/10.1590/18094449201700500018.

MACHADO, Maria das Dores Campos. O discurso cristão sobre a "ideologia de gênero". Rev. Estud. Fem., Florianópolis , v. 26, n. 2, e47463, 2018 . Disponível em <http://www.scielo.br/scielo.php?script=sci_arttext\&pid=S0104-

Educação, Psicologia e Interfaces, Volume 4, Número 2, p. 35-50, Abril/Junho, 2020.

ISSN: 2594-5343. DOI: 10.37444/issn-2594-5343.v4i2.226 
026X2018000200212\&lng=pt\&nrm=iso >. Acesso em 01 dez. 2018. Doi: https://doi.org/10.1590/1806-9584-2018v26n247463.

MISKOLCI, Richard. Exorcizando um fantasma: os interesses por trás do combate à “ideologia de gênero”. Caderno Pagu , Campinas, n. 53, e185302, 2018. Disponível em <http://www.scielo.br/scielo.php?script=sci_arttext\&pid=S0104-

$83332018000200402 \& \operatorname{lng}=e n \& n r m=i s o>$. Acesso em 02 de set. de 2019. Doi: https://doi.org/10.1590/18094449201800530002 .

MISKOLCI, Richard; CAMPANA, Maximiliano. "Ideologia de gênero": notas para uma genealogia de um moral moral contemporâneo. Soc. estado. , Brasília, v. 32, n. 3, p. 725-748, dezembro de 2017. Disponível em <http://www.scielo.br/scielo.php?script=sci_arttext\&pid=S010269922017000300725\&lng=en\&nrm=iso>. Acesso em 02 de maio de 2019. Doi: https://doi.org/10.1590/s0102-69922017.3203008 .

NORONHA, Ceci Vilar; DALTRO, Maria Esther. A violência masculina é dirigida por Eva ou Maria ?. Cafajeste. Saúde Pública, Rio de Janeiro, v. 7, n. 2, p. 215-231, junho de 1991. Disponível em $<$ http://www.scielo.br/scielo.php?script=sci_arttext\&pid=S0102311X1991000200007\&lng=en\&nrm=iso>. Acesso em 02 de maio de 2019. https://doi.org/10.1590/S0102-311X1991000200007 .

PEREIRA, Pedro Paulo Gomes. Judith Butler e a pomba-gira. Cad. Pagu, Campinas, n. 53, e185304, 2018. Disponível em $<$ http://www.scielo.br/scielo.php?script=sci_arttext\&pid=S010483332018000200404\&lng=pt\&nrm=iso>. Acesso em: 02 jun 2019. Epub 11-Jun2018. https://doi.org/10.1590/18094449201800530004.

REIS, Toni; EGGERT, Edla. Ideologia de gênero: uma falácia construída sobre os planos de educação brasileiros. Educ. Soc., Campinas, v. 38, n. 138, p. 9-26, Jan. 2017. Disponível em: <http://www.scielo.br/scielo.php?script=sci_arttext\&pid=S0101$73302017000100009 \& \operatorname{lng}=\mathrm{en} \& \mathrm{nrm}=\mathrm{iso}>$. Acesso em: 02 maio 2019. https://doi.org/10.1590/es0101-73302017165522.

RIOS, Roger Raupp e col. Laicidade e Conselho Federal de Psicologia: Dinâmica Institucional e Profissional em Perspectiva Jurídica. Psicol. cienc. prof. , Brasília, v. 37, n. 1, p. 159-175, janeiro de 2017. Disponível em $<$ http://www.scielo.br/scielo.php?script=sci_arttext\&pid=S141498932017000100159\&lng=en\&nrm=iso>. Acesso em 02 de maio de 2018. https://doi.org/10.1590/1982-3703002612016 .

SILVA, Ivanderson Pereira da. Em busca de significados para a expressão "ideologia de gênero”. Educ. rev., Belo Horizonte , v. 34, e190810, 2018 . Disponível em 
<http://www.scielo.br/scielo.php?script=sci_arttext\&pid=S0102-

46982018000100186\&lng=pt\&nrm=iso $>$. Acesso em 02 maio 2019. Doi:

https://doi.org/10.1590/0102-4698190810.

\section{Agradecimentos}

A UNIVALE - Universidade Vale do Rio Doce, pelo financiamento do projeto de pesquisa "Gênero e Território: sociabilidades, fatores geracionais e suas inter-relações", do qual esta publicação é resultante.

\section{Credenciais da/os autora/es}

NOVAES, Edmarcius Carvalho Novaes. Professor e pesquisador na Universidade Vale do Rio Doce. Doutorando em Ciências Humanas pela Universidade Federal de Santa Catarina, na área de concentração em Estudos de Gênero. Mestre em Gestão Integrada do Território (UNIVALE) e Especialista em Gênero e Diversidade na Escola (UFMG). E-mail: edmarcius@hotmail.com

ANDRADE, Jakeline Soares. Graduada em Pedagogia pela Universidade Vale do Rio Doce. E-mail: jakelinesoares942@gmail.com

SANTOS. Tainara Adriane dos. Graduada em Pedagogia pela Universidade Vale do Rio Doce. E-mail: tsantosecosta@gmail.com

Endereço para correspondência: Edmarcius Carvalho Novaes. Universidade Vale do Rio Doce, Faculdade de Ciências, Educação e Letras. Rua Israel Pinheiro, 2000, Universitário. CEP: 35030440 - Governador Valadares, MG - Brasil

Como citar este artigo (Formato ABNT): NOVAES, Edmarcius Carvalho; ANDRADE, Jakeline Soares; SANTOS, Tainara Adriane dos. Ideologia de Gênero: o que dizem periódicos brasileiros?. Educação, Psicologia e Interfaces, v. 4, n.2, p. 3550, 2020. Doi: 10.37444/issn-2594-5343.v4i2.226

Recebido: $10 / 01 / 2020$.

Aceito: 20/04/2020.

Educação, Psicologia e Interfaces, Volume 4, Número 2, p. 35-50, Abril/Junho, 2020.

ISSN: 2594-5343. DOI: 10.37444/issn-2594-5343.v4i2.226 